\title{
Time-Delay LPV System Control and Its Application in Chatter Suppression of the Milling Process
}

\author{
Dazhong Wang, Shujing Wu, and Lei Wan \\ Shanghai University of Engineering Science, Shanghai 201620, China \\ Correspondence should be addressed to Dazhong Wang; wdzh168@hotmail.com
}

Received 14 June 2014; Revised 2 November 2014; Accepted 29 November 2014

Academic Editor: George S. Dulikravich

Copyright ( 2015 Dazhong Wang et al. This is an open access article distributed under the Creative Commons Attribution License, which permits unrestricted use, distribution, and reproduction in any medium, provided the original work is properly cited.

\begin{abstract}
This paper proposed a methodology for the control of model following control system (MFCS) approach to time-delay linear parameter-varying (LPV) system. The method incorporates a state control law which makes the output error zero, the bounded property of the internal states for the control is given, and the utility of this control design is guaranteed. Numerical example is given to demonstrate the effectiveness and less conservativeness of the proposed methods. The proposed control methodology is demonstrated on chatter suppression in the milling process.
\end{abstract}

\section{Introduction}

Time-delay is commonly encountered in various physical and engineering systems such as aircraft, biological systems, and networked control systems. In [1], the authors proposed processing short-term and long-term information with a combination of polynomial approximation techniques and timedelay neural networks. The paper [2] proposed adaptive digital predistortion of wireless power amplifiers/transmitters using dynamic real-valued focused time-delay line neural networks. Also, a new strategy for optimal control of continuous tandem cold metal rolling was designed in [3, 4] obtained robust power control of multilink single-sink optical networks with time-delays. Some other related results can refer to [5-9].

Stability analysis and control synthesis problems of linear parameter-varying (LPV) continuous-time systems where the state-space matrices depend on time-varying parameters, whose values are not known a priori but can be measured in real time, have received considerable attention recently [10-12]. Most of the abovementioned techniques have been applied to practical systems. Control designs for LPV systems such as missiles, aircrafts and spacecrafts, energy production systems, mechatronic systems, congestion in computernetworks, and web servers [13-16] have been investigated. The approach of using LPV models has computational advantages over other controller synthesis methods for nonlinear systems because the formulation is close to the linear system counterpart. The approach also comes with a theoretical validity, since it can be shown that the closed loop system meets certain specifications.

Model following control system (MFCS) methods have received considerable attention over the last decades. The paper [17] deals with robustness to plant parameter perturbations and sensitivity to disturbances of two-loop control structures containing a model of the controlled plant and two PID controllers. In [18], a robust model following control law based on hyper stability theory will be derived for uncertain systems with input nonlinearities.

Design of MFCS for nonlinear neutral system with timedelays and disturbances is discussed; it was proposed by Okubo [19] for a family of plants with separable linear and nonlinear part. In previous studies, a method of linear MFCS for time-delays system was proposed by [20]. These methods are developed to make the ultimate bounded of the MFCS error arbitrarily small or guarantee that MFCS error decreases asymptotically to zero.

The paper [21] has proposed a study of the model following control in which the considered system had linear timedelay. Despite the fact that the method with milling vibration control has already been verified, the considered model is not typical. So, the MFCS uses directly time-delay for an input 
time-delay system and the system can be transformed into a linear time invariant one by using a variable transformation. Thus, it is easy to design controllers with enough stability and performance based on MFCS theory. The objective of this paper is to design a MFCS scheme for time-delay LPV system whose state-space matrices depend affinely on a set of time-delay parameters that is bounded. The proposed control methodology is demonstrated on chatter suppression in the milling process. This research is a prolongation of paper [21].

This paper is organized as follows. In Section 2, we formulate the time-delay LPV system with disturbances, give the reference model, and tackle the design of the MFCS for the time-delay LPV system. In Section 3, problem of the chatter control in the milling process is proposed. In Section 4, some preliminary numerical simulations and experiment are reported. Finally, Section 5 concludes this paper.

\section{MFCS for Time-Delay LPV System}

2.1. The Problem Formulation. Consider the following timedelay LPV system:

$$
\begin{aligned}
& \dot{x}(t)=\sum_{i=0}^{n} A_{i}(\rho) x\left(t-h_{i}\right)+\sum_{i=0}^{n} B_{i} u\left(t-h_{i}\right)+d(t), \\
& y(t)=C x(t)+d_{0}(t),
\end{aligned}
$$

where $A_{i}(\rho) \in R^{n \times n}, B_{i} \in R^{n \times I}$, and $C \in R^{I \times n}$ are constant matrices of appropriate dimensions. $x(t) \in R^{n}, u(t) \in R^{l}$, and $y(t) \in R^{l}$ are the system state vector, control input vector, and available states output vector of the system, respectively. $d(t) \in R^{n}$ and $d_{0}(t) \in R^{n}$ are bounded disturbances; $h_{i}$ are time-delays.

The reference model is given below, which is assumed to be controllable and observable [20]:

$$
\begin{aligned}
& \dot{x}_{m}(t)=A_{m} x_{m}(t)+B_{m} r_{m}(t), \\
& y_{m}(t)=C_{m} x_{m}(t) .
\end{aligned}
$$

Here, $x_{m}(t) \in R^{n_{m}}, r_{m}(t) \in R^{l_{m}}$, and $y_{m}(t) \in R^{l_{m}}$ are the state vector, input vector, and output vector of the reference model system, respectively, and $A_{m} \in R^{n_{m} \times n_{m}}, B_{m} \in R^{n_{m} \times I}$, and $C_{m} \in R^{I \times n_{m}}$ are constant matrices. Output error is given as

$$
e(t)=y(t)-y_{m}(t)
$$

The aim of the control system design is to obtain a control law which makes the output error zero and keeps the internal states bounded.

\subsection{Design of the System for the Time-Delay}

Definition 1. The time-delay factor $\sigma$ is defined as [22]

$$
\sigma: F \longrightarrow F, \quad f(t) \longrightarrow f(t-h) .
$$

Here, $F$ is defined on the continuous space $\psi\left(\left[-h_{i}, 0\right], R^{n}\right)$. Let $p=d / d t, \sigma_{i}=e^{p h_{i}}$, and $\sigma_{i} v(t)=v\left(t-h_{i}\right)$.
Then, using $\sigma_{i}$, we can represent system (1) as

$$
\begin{aligned}
& \dot{x}(t)=A\left(\rho, \sigma_{i}\right) x(t)+B\left(\sigma_{i}\right) u(t)+d(t), \\
& y(t)=C x(t)+d_{0}(t) .
\end{aligned}
$$

Here, $A\left(\rho, \sigma_{i}\right)=\sum_{i=0}^{n} A_{i}(\rho) \sigma_{i}$ and $B\left(\sigma_{i}\right)=\sum_{i=0}^{n} B_{i} \sigma_{i}$.

Without loss of generality, we make the following three assumptions [23].

Assumption 2. $\left[A\left(\rho, \sigma_{i}\right), B\left(\sigma_{i}\right)\right]$ is controllable and $[C, A(\rho$, $\left.\sigma_{i}\right)$ ] is observable; that is, the following conditions are held:

$$
\begin{gathered}
\operatorname{rank}\left[p I-A\left(\rho, \sigma_{i}\right) B\left(\sigma_{i}\right)\right]=n, \\
\operatorname{rank}\left[\begin{array}{c}
p I-A\left(\rho, \sigma_{i}\right) \\
C
\end{array}\right]=n .
\end{gathered}
$$

Assumption 3. Zeros of $C\left[p I-A\left(\rho, \sigma_{i}\right)\right]^{-1} B\left(\sigma_{i}\right)$ are stable.

Assumption $4\left(\left|p I-A\left(\rho, \sigma_{i}\right)\right| \neq 0\right)$. It follows from (2) and (6) that

$$
\begin{aligned}
x_{m}(t)= & {\left[p I-A_{m}\right]^{-1} B_{m} r_{m}(t), } \\
x(t)= & {\left[p I-A\left(\rho, \sigma_{i}\right)\right]^{-1} B\left(\sigma_{i}\right) u(t) } \\
& +\left[p I-A\left(\rho, \sigma_{i}\right)\right]^{-1} d(t) .
\end{aligned}
$$

Furthermore, we have by using (3), (7), and (9),

$$
\begin{aligned}
y(t)= & C\left[p I-A\left(\rho, \sigma_{i}\right)\right]^{-1} B\left(\sigma_{i}\right) u(t) \\
& +C\left[p I-A\left(\rho, \sigma_{i}\right)\right]^{-1} d(t)+d_{0}(t), \\
y_{m}(t) & =C_{m}\left[p I-A_{m}\right]^{-1} B_{m} r_{m}(t) .
\end{aligned}
$$

Then, the representations of input-output equations are given as

$$
\begin{aligned}
& D(p) y(t)=N\left(\rho, \sigma_{i}, p\right) u(t)+w(t), \\
& D_{m}(p) y_{m}(t)=N_{m}(p) r_{m}(t),
\end{aligned}
$$

where

$$
\begin{gathered}
C\left[p I-A\left(\rho, \sigma_{i}\right)\right]^{-1} B\left(\sigma_{i}\right)=\frac{N\left(\rho, \sigma_{i}, p\right)}{D(p)}, \\
N\left(\rho, \sigma_{i}, p\right)=C \operatorname{adj}\left[p I-A\left(\rho, \sigma_{i}\right)\right] B\left(\sigma_{i}\right), \\
D(p)=\left|p I-A\left(\rho, \sigma_{i}, p\right)\right|, \\
C_{m}\left[p I-A_{m}\right]^{-1} B_{m}=\frac{N_{m}(p)}{D_{m}(p)}, \\
N_{m}(p)=C_{m} \operatorname{adj}\left[p I-A_{m}\right] B_{m}, \\
D_{m}(p)=\left|p I-A_{m}\right| .
\end{gathered}
$$

Let

$$
\begin{aligned}
& N\left(\rho, \sigma_{i}, p\right)=\operatorname{diag}\left(\sigma^{\eta_{i}}\right) N_{r}\left(\rho, \sigma_{i}\right)+\widetilde{N}\left(\rho, \sigma_{i}, p\right), \\
& N_{m}(p)=\operatorname{diag}\left(\sigma^{\eta_{m_{i}}}\right) N_{m_{r}}+\widetilde{N}_{m}(p), \\
& N_{r}\left(\rho, \sigma_{i}\right)=\bar{N}_{r}\left(\rho, \sigma_{i}\right)+\widehat{N}_{r},
\end{aligned}
$$

where $\partial_{r_{i}} \widetilde{N}\left(\rho, \sigma_{i}, p\right)<\eta_{i}$ and $\partial_{r_{i}} \widetilde{N}_{m}(p)<\eta_{m_{i}}$. 
$\widehat{N}_{r}$ is fixed matrix of $l \times l$, as well as $\widehat{N}_{r} \neq 0$. Let $D_{d}(p)$ be a scalar characteristic polynomial of disturbances. Disturbances $d(t)$ and $d_{0}(t)$ satisfy $D_{d}(p) d(t)=0, D_{d}(p) d_{0}(t)=0$. The first step of design is a monic and stable polynomial $T(p)$. Then, $R\left(\rho, \sigma_{i}, p\right)$ and $S\left(\rho, \sigma_{i}, p\right)$ can be obtained from

$$
T(p) D_{m}(p)=D_{d}(p) D(p) R\left(\rho, \sigma_{i}, p\right)+S\left(\rho, \sigma_{i}, p\right)
$$

where the degree of each polynomial is $\partial T(p)=\lambda$, $\partial D_{m}(p)=n_{m}, \partial D_{d}(p)=n_{d}, \partial R\left(\rho, \sigma_{i}, p\right)=\lambda+n_{m}-$ $n_{d}-n$, and $\partial S\left(\rho, \sigma_{i}, p\right) \leq n_{d}+n-1$. And $T(p)$, $D_{m}(p), D_{d}(p), D(p), R\left(\rho, \sigma_{i}, p\right)$, and $S\left(\rho, \sigma_{i}, p\right)$ are polynomials. Let $Q(p)=\operatorname{diag}\left(p^{\lambda+n_{m}-n+\eta_{i}}\right)+\widetilde{Q}(p),(i=1,2, \ldots, l)$; $\widetilde{Q}(p)$ is a polynomial matrix which is stable and $\partial_{r_{i}} \widetilde{Q}(p)<$ $\lambda+n_{m}-n+\eta_{i}$. Then, the following form is obtained:

$$
\begin{aligned}
T(p) & D_{m}(p) e(t) \\
= & D_{d}(p) D(p) R\left(\rho, \sigma_{i}, p\right) y(t) \\
& +S\left(\rho, \sigma_{i}, p\right) y(t)-T(p) N_{m}(p) r_{m}(t) \\
= & \left(D_{d}(p) R\left(\rho, \sigma_{i}, p\right) N\left(\rho, \sigma_{i}, p\right)\right. \\
& \left.\quad-Q(p) N_{r}\left(\rho, \sigma_{i}, p\right)\right) u(t) \\
+ & Q(p)\left(\bar{N}_{r}\left(\rho, \sigma_{i}, p\right)+\widehat{N}_{r}\right) u(t) \\
+ & S\left(\rho, \sigma_{i}, p\right) y(t)-T(p) N_{m}(p) r_{m}(t) .
\end{aligned}
$$

The control law $u(t)$ can be obtained by making the righthand side of (12) be equal to zero.

Thus,

$$
\begin{aligned}
u(t)= & -\widehat{N}_{r}^{-1} \bar{N}_{r}\left(\rho, \sigma_{i}, p\right) u(t)-\widehat{N}_{r}^{-1} Q^{-1}(p) \\
& \cdot\left(D_{d}(p) R\left(\rho, \sigma_{i}, p\right) N\left(\rho, \sigma_{i}, p\right)\right. \\
& \left.-Q(p) N_{r}\left(\rho, \sigma_{i}, p\right)\right) u(t) \\
& -\widehat{N}_{r}^{-1} Q^{-1}(p) S\left(\rho, \sigma_{i}, p\right) y(t) \\
& +N_{r}^{-1} Q^{-1}(p) T(p) N_{m}(p) r_{m}(t) .
\end{aligned}
$$

For using no derivatives of signals in control input $u(t)$, we assume that $n_{m}-\eta_{m i} \geq n-\eta_{i}, \lambda \geq n_{d}+2 n-n_{m}-1-\eta_{i}$. The state-space expression of $u(t)$ can be shown as follows:

$$
\begin{aligned}
u(t)= & -J_{0}\left(\rho, \sigma_{i}\right) u(t)-H_{1}\left(\rho, \sigma_{i}\right) \xi_{1}(t) \\
& -J_{2}\left(\rho, \sigma_{i}\right) y(t)-H_{2}\left(\rho, \sigma_{i}\right) \xi_{2}(t) \\
& +E_{3} r_{m}(t)+H_{3} \xi_{3}(t),
\end{aligned}
$$

where $u_{m}(t)$ is outside signal. $\xi_{i}(t)(i=1,2,3)$ is satisfying the following constraints [19]: $\dot{\xi}_{1}(t)=F_{1} \xi_{1}(t)+G_{1} u(t), \dot{\xi}_{2}(t)=$ $F_{2} \xi_{2}(t)+G_{2} y(t)$, and $\dot{\xi}_{3}(t)=F_{3} \xi_{3}(t)+G_{3} r_{m}(t)$. Since $\mid p I-$ $F_{3}|=| Q(p) \mid$ is stable polynomial and $r_{m}(t)$ is reference input, $\xi_{3}(t)$ is bounded. The connections between the polynomial matrices and the system matrices are given as [22]

$$
\begin{aligned}
& J_{0}\left(\rho, \sigma_{i}\right)=\widehat{N}_{r}^{-1} \bar{N}_{r}(\rho, p), \\
& \begin{aligned}
& H_{1}\left(\rho, \sigma_{i}\right)\left[p I-F_{1}\right]^{-1} G_{1} \\
&= \widehat{N}_{r}^{-1} Q^{-1}(p) \\
& \quad \times\left(D_{d}(p) \cdot R\left(\rho, \sigma_{i}, p\right) N\left(\rho, \sigma_{i}, p\right)-Q(p) N_{r}\left(\rho, \sigma_{i}\right)\right),
\end{aligned} \\
& J_{2}\left(\rho, \sigma_{i}\right)+H_{2}\left(\rho, \sigma_{i}\right)\left[p I-F_{2}\right]^{-1} G_{2} \\
& \quad=\widehat{N}_{r}^{-1} Q^{-1}(p) S\left(\rho, \sigma_{i}, p\right), \\
& J_{3}+H_{3}\left[p I-F_{3}\right]^{-1} G_{3}=\widehat{N}_{r}^{-1} Q^{-1}(p) T(p) N_{m}(p) .
\end{aligned}
$$

Therefore, $u(t)$ of (17) is obtained from $e(t)$. The MFCS can be realized if the system internal states are bounded.

2.3. The Bounded Property of Internal States. Let $z_{s}(t)=$ $\left[x^{T}(t), \xi_{1}^{T}(t), \xi_{2}^{T}(t), u^{T}(t)\right]^{T}$; removing the $u(t)$ from $(6) \sim(7)$ and (18) and (19), the system is given by

$$
\begin{aligned}
& E_{s} \dot{z}_{s}(t)=A_{s}\left(\rho, \sigma_{i}\right) z_{s}(t)+d_{s}(t), \\
& y_{s}(t)=C_{s} z_{s}(t)+d_{s 0}(t),
\end{aligned}
$$

where

$$
\begin{gathered}
C_{s}=\left[\begin{array}{l}
C \\
0 \\
0 \\
0
\end{array}\right]^{T}, \quad E_{s}=\left[\begin{array}{llll}
I & 0 & 0 & 0 \\
0 & I & 0 & 0 \\
0 & 0 & I & 0 \\
0 & 0 & 0 & 0
\end{array}\right], \\
d_{s 0}(t)=\left[\begin{array}{c}
d_{0}(t) \\
0 \\
0 \\
0
\end{array}\right], \quad A_{s}\left(\rho, \sigma_{i}\right)=\left[\begin{array}{cccc}
A & 0 & 0 & B \\
0 & F_{1} & 0 & G_{1} \\
G & 0 & F_{2} & 0 \\
J_{2} & H_{1} & H_{2} & J_{0}
\end{array}\right], \\
A=A\left(\rho, \sigma_{i}\right), \quad G=G_{2} C, \quad J_{2}=-J_{2}\left(\rho, \sigma_{i}\right) C, \\
H_{1}=-H_{1}\left(\rho, \sigma_{i}\right), \quad B=B\left(\sigma_{i}\right), \quad H_{2}=-H_{2}\left(\rho, \sigma_{i}\right), \\
J_{0}=-I-J_{0}\left(\rho, \sigma_{i}\right) .
\end{gathered}
$$

It should be pointed out that the internal state of (1) is equal to the one of (20). So the bounded property of internal states of (1) is turned out to be that $z_{s}(t)$ is bounded. Characteristic polynomial $\left|p E_{s}-A_{s}\left(\rho, \sigma_{i}\right)\right|$ of the system can be calculated as follows [24]:

$$
\begin{aligned}
\left|p E_{s}-A_{s}\left(\rho, \sigma_{i}\right)\right| \\
=\left|p I-A\left(\rho, \sigma_{i}\right)\right|\left|p I-F_{1}\right|\left|p I-F_{2}\right| \\
\times \mid I+J_{0}\left(\rho, \sigma_{i}\right)+H_{1}\left(\rho, \sigma_{i}\right)\left[p I-F_{1}\right]^{-1} G_{1} \\
\quad+\left(J_{2}\left(\rho, \sigma_{i}\right)+H_{2}\left(\rho, \sigma_{i}\right)\left[p I-F_{2}\right]^{-1} G_{2}\right) \\
\quad \times C[p I-A] B\left(\sigma_{i}\right) \mid .
\end{aligned}
$$


From $\left|p I-F_{i}\right|=|Q(p)|$ and $\left|p I-A\left(\rho, \sigma_{i}\right)\right|=D(p)$ into (22), we have

$$
\begin{aligned}
& \left|p E_{s}-A_{s}\left(\rho, \sigma_{i}\right)\right| \\
& \quad=T(p)^{l} D(p) D_{m}(p)^{l}|Q(p)|\left|\widehat{N}_{r}\right|^{-1} \frac{\left|N\left(\rho, \sigma_{i}, p\right)\right|}{D(p)^{l}} .
\end{aligned}
$$

On the other hand,

$$
\begin{aligned}
C\left[p I-A\left(\rho, \sigma_{i}\right)\right]^{-1} B\left(\sigma_{i}\right) & =\frac{N\left(\rho, \sigma_{i}, p\right)}{D(p)^{l}} \\
& =U(p)^{-1} V\left(\rho, \sigma_{i}, p\right),
\end{aligned}
$$

where $V\left(\rho, \sigma_{i}, p\right)$ is the zeros polynomial of $C[p I-A(\rho$, $\left.\left.\sigma_{i}\right)\right]^{-1} B\left(\sigma_{i}\right)$ (left coprime decomposition). So $\left|N\left(\rho, \sigma_{i}, p\right)\right|=$ $D(p)^{l-1}\left|V\left(\rho, \sigma_{i}, p\right)\right|$; we have

$$
\begin{aligned}
& \left|p E_{s}-A_{s}\left(\rho, \sigma_{i}\right)\right| \\
& \quad=\left|\widehat{N}_{r}\right|^{-1} T(p)^{l} D_{m}(p)^{l}|Q(p)|\left|V_{s}\left(\rho, \sigma_{i}, p\right)\right| .
\end{aligned}
$$

Hence, we can conclude that $A_{s}\left(\rho, \sigma_{i}\right)$ is a stable system matrix due to the fact that $T(p), D_{m}(p),|Q(p)|$, and $\left|V\left(\rho, \sigma_{i}, p\right)\right|$ are stable polynomials.

Lemma 5. (1) If $V\left(\rho, \sigma_{i}, p\right)$ could be factorized into $\sigma_{i}$ and $\rho$ contained polynomial $V\left(\rho, \sigma_{i}\right)$ and $p$ contained polynomial $V(p)$, that is, $V\left(\rho, \sigma_{i}, p\right)=V\left(\rho, \sigma_{i}\right) V(p)$, then, at time when all $\sigma_{i}$ and $\rho$, roots of $V\left(\rho, \sigma_{i}\right)=0$, satisfy $\left|\rho, \sigma_{i}\right|>1$, then $V\left(\rho, \sigma_{i}\right)$ was stable. While $V(p)$ was stable, $V\left(\rho, \sigma_{i}, p\right)$ was stable either; (2) If $V\left(\rho, \sigma_{i}, p\right)$ could not be factorized into polynomial $V\left(\rho, \sigma_{i}\right)$ and polynomial $V(p)$, then Nyquist stability criterion should be adopted [20].

Lemma 6. For the controlled object (20), the rank of $E_{s}$ and the degree about $p$ of $\left|p E_{s}-A_{s}\left(\rho, \sigma_{i}\right)\right|$ will be [22]

$$
\begin{aligned}
\operatorname{rank} E_{s} & =\operatorname{deg}\left|p E_{s}-A_{s}\left(\rho, \sigma_{i}\right)\right| \\
& =n+2 \sum_{i=1}^{l}\left(\lambda+n_{m}-n+\eta_{i}\right) .
\end{aligned}
$$

From the above discussions, we have the main following result.

Theorem 7. With controlled system (1) and reference model (2) and (3), all the internal states are bounded and output error $e(t)=y(t)-y_{m}(t)$ is asymptotically to converge to zero in the design of the MFCS for the time-delay LPV system with disturbances, if the following conditions are held.

(1) $\left[A\left(\rho, \sigma_{i}\right), B\left(\sigma_{i}\right)\right]$ is controllable and $\left[C, A\left(\rho, \sigma_{i}\right)\right]$ is observable, that is,

(2) $\operatorname{rank} E_{s}=\operatorname{deg}\left|p E_{s}-A_{s}\left(\rho, \sigma_{i}\right)\right|$.

(3) Disturbances $d(t)$ and $d_{0}(t)$ are bounded.

(4) Zeros of $C\left[p I-A\left(\rho, \sigma_{i}\right)\right]^{-1} B\left(\sigma_{i}\right)$ are stable.

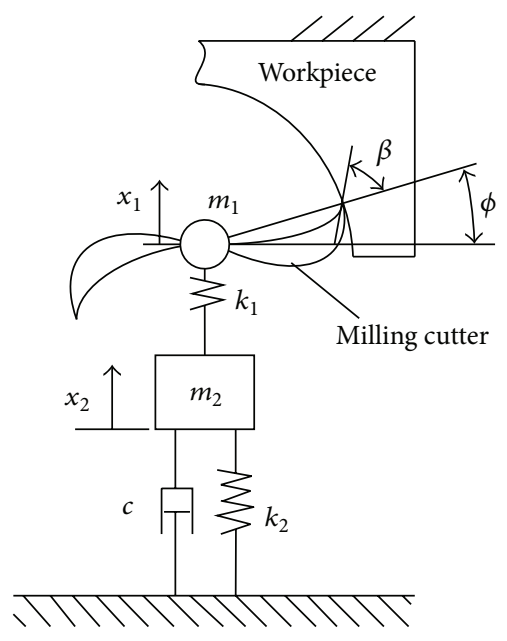

FIGURE 1: Milling process [25, 26].

\section{Chatter Suppression in the Milling Process}

3.1. The Time-Delay LPV System in the Milling Process. In the milling process, the workpiece is clamped and fed to a rotating multitooth cutter. The geometry of the milling process is as shown in Figure 1 [25]. The cutter has two blades that are used to remove material from the workpiece. The force acting on the tool is a function of not only the current displacement of the tool but also the surface characteristics and hence the displacement at the previous tool pass. This induces a time-delay into the system. The force depends also on the angular position of the blade, which plays the role of the time-varying parameter. The state-space model of this system can be represented as follows $[25,26]$ :

$$
\begin{aligned}
& m_{1} \ddot{x}_{1}+k_{1}\left(x_{1}-x_{2}\right)=k \sin (\phi+\beta) \psi(t)-w, \\
& m_{2} \ddot{x}_{2}+c \dot{x}_{2}+k_{1}\left(x_{2}-x_{1}\right)+k_{2} x_{2}=u
\end{aligned}
$$

where $\psi(t)=\sin (\phi)\left[x_{1}(t-h(t))-x_{1}(t)\right], k_{1}$ and $k_{2}$ are the stiffness of the two springs, $c$ is the damping coefficient, $m_{1}$ and $m_{2}$ are the masses of the blade and the tool, and $x_{1}$ and $x_{2}$ are the displacements of the blade and the tool. The angle $\beta$ depends on the particular material and the tool used.

The angle $\phi$ denotes the angular position of the blade, $k$ denotes the cutting force coefficient, and $w$ denotes the disturbance. The time-delay which is the time interval between two successive cuts is denoted by $h(t)$ and is approximated to be $\pi / \omega$ where $\omega$ is the rotation speed of the blade.

3.2. The State-Space Representation of the Time-Delay LPV System. In this subsection, we seek to design an LPV controller to attenuate the effect of the disturbance force $w(t)$. An output feedback MFCS control is to be designed. For this purpose, we add a control force at mass $m_{2}$. The controlled variable vector is composed of the displacements of the two masses and the control force. The displacement of the mass $m_{2}$ is assumed to be the only measurable output. 
Let $x=\left[\begin{array}{llll}x_{1} & x_{2} & \dot{x}_{1} & \dot{x}_{2}\end{array}\right]^{T}$ be the state vector. Then, the state-space representation of the time-delay LPV system can be written as follows [26]:

$$
\begin{aligned}
& \dot{x}(t)=A_{1}(\eta) x(t)+A_{2}(\eta) x(t-h(t))+B u(t)+D w(t), \\
& y(t)=C x(t),
\end{aligned}
$$

where

$$
\begin{gathered}
A_{1}(\eta)=\left[\begin{array}{ccccc}
0 & 0 & 1 & 0 \\
0 & 0 & 0 & 1 \\
-10.34+\eta_{1} & 10 & 0 & 0 \\
5 & & -15 & 0 & -0.25
\end{array}\right], \\
A_{2}(\eta)=\left[\begin{array}{cccc}
0 & 0 & 0 & 0 \\
0 & 0 & 0 & 0 \\
0.34-\eta_{1} & 0 & 0 & 0 \\
0 & 0 & 0 & 0
\end{array}\right], \quad B=\left[\begin{array}{c}
0 \\
0 \\
0 \\
0.5
\end{array}\right], \\
D=\left[\begin{array}{cccc}
0 & 0 & -1 & 0
\end{array}\right]^{T}, \quad C=\left[\begin{array}{llll}
0 & 1 & 0 & 0
\end{array}\right] .
\end{gathered}
$$

\section{Numerical Simulation}

4.1. Simulation. In this section, we present some numerical simulations which demonstrate the effectiveness and flexibility of the proposed design approach. The initial value function is $x_{0}(t)=\left[\begin{array}{lll}1 & 1 & -3\end{array}\right]^{T}$. Time-delay $h_{1}=0.5$. Based on the system (28), we have

$$
\begin{aligned}
\dot{x}(t) & =\left[\begin{array}{cccc}
0 & 0 & 1 & 0 \\
0 & 0 & 0 & 1 \\
\Lambda & 10 & 0 & 0 \\
5 & -15 & 0 & -0.25
\end{array}\right] x(t)+\left[\begin{array}{c}
0 \\
0 \\
0 \\
0.5
\end{array}\right] u(t) \\
& +\left[\begin{array}{c}
0 \\
0 \\
-1 \\
0
\end{array}\right] w(t), \\
y(t) & =\left[\begin{array}{llll}
0 & 1 & 0 & 0
\end{array}\right] x(t),
\end{aligned}
$$

where $\Lambda=-10.34+\eta_{1}+0.34 \sigma_{1}-\eta_{1} \sigma_{1}$. We have formulated the process as time-delayed system which is parametrically dependent on the cutting stiffness $k$ (constant in the milling process). Meet cutting stiffness conditions: the displacements of the masses $m_{2}\left(x_{2}(t)\right)$ and the displacements of the masses $m_{1}\left(x_{1}(t)\right)$ are equal and opposite. In the simulation, let $T(p)=p+5, Q(p)=(p+6)^{2}, D_{d}(p)=p, F_{i}=\left[\begin{array}{cc}0 & 1 \\ -36 & -12\end{array}\right]$, and $G_{i}=\left[\begin{array}{l}0 \\ 1\end{array}\right],(i=1,2,3)$. The reference model is given by $y_{m}(t)=-x_{1}(t)=\sin 0.5 t+8$.

Consider the disturbances: $w(t)=0.5,(30 \leq t \leq$ 55). In the responses of the MFCS for the time-delay LPV system, the output signal $y(t)=x_{2}(t)$ follows the reference $y_{m}(t)=-x_{1}(t)$, even though disturbances exist in the system; see Figure 2. The milling system stiffness and tool path planning are guaranteed, even in the case when disturbances can ensure system stability. For diagram of MFCS for chatter control in the milling, see Figure 3.

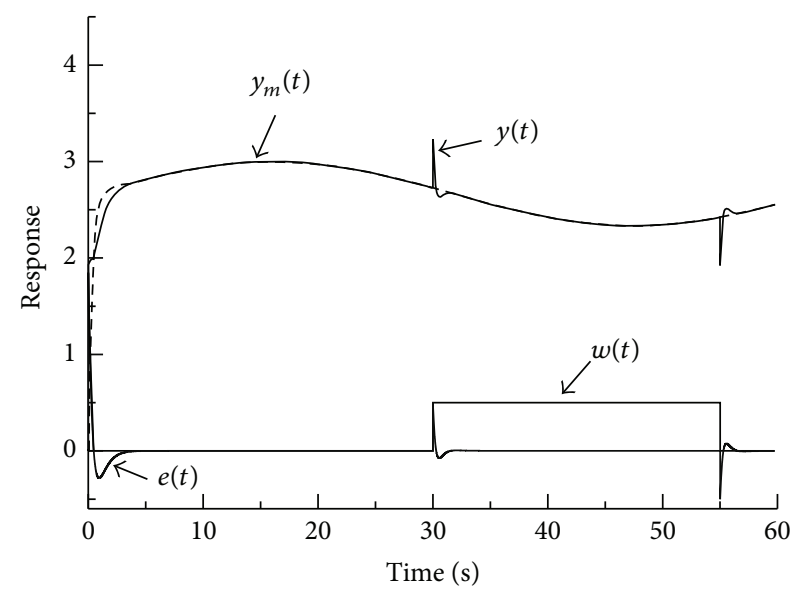

FIGURE 2: Control of chatter suppression in the milling process.

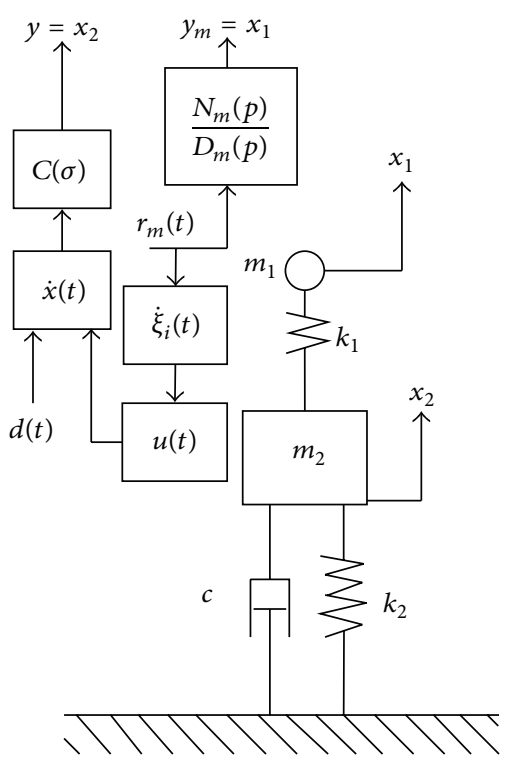

FIGURE 3: Diagram of MFCS for chatter suppression in the milling.

4.2. Experiment. The experimental site is shown in Figure 4. The Laboratory instruments are data acquisition card, charge amplifier, power amplifier, and acceleration amplifier. The experimental data can be found in Table 1 and the finished workpiece surface is shown in Figures 5, 6, and 7.

It can be found from Figures 5-7 that the quality of the finished workpiece surface improved significantly under the control of this approach.

\section{Conclusion}

In this paper, we considered the design of MFCS for timedelay linear LPV. For the sake of use in practical applications, chatter suppression in the milling process of LPV systems is investigated. Numerical simulation is provided to demonstrate the usefulness and the practicality of the proposed LPV control scheme. 


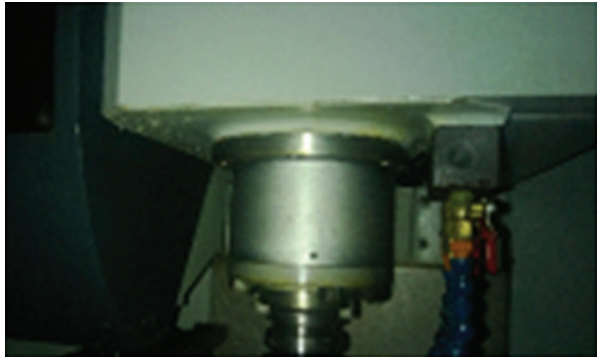

(a)

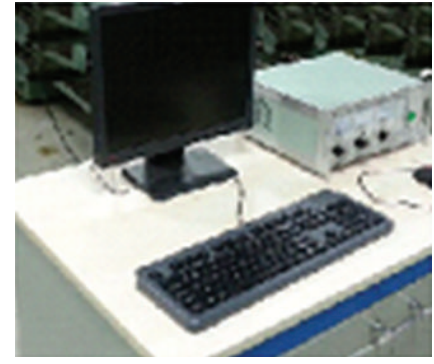

(b)

FIgURE 4: The experimental site.

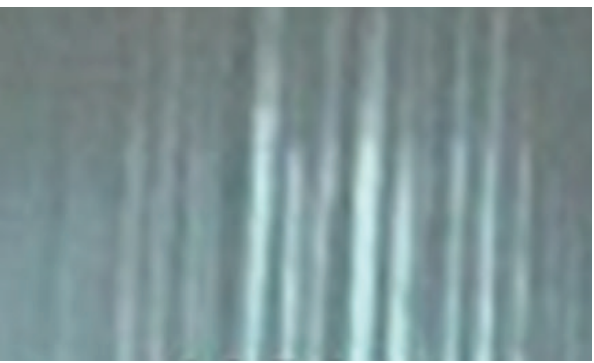

(a) Without control

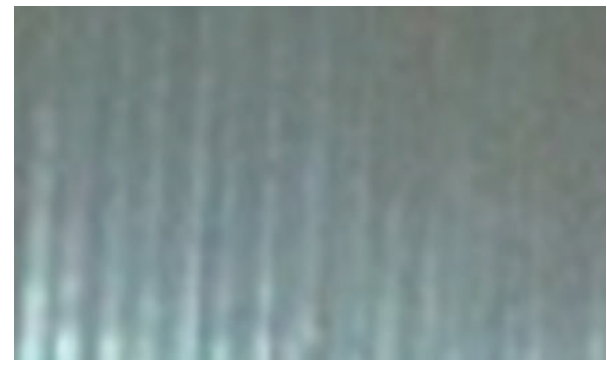

(b) With control

FIGURE 5: Machined surface quality. Workpiece: 302; tool: YT15; cutting parameters: $v=1 \mathrm{~m} / \mathrm{s}, \alpha_{p}=3 \mathrm{~mm}, f=0.1 \mathrm{~mm} / \mathrm{r}$.

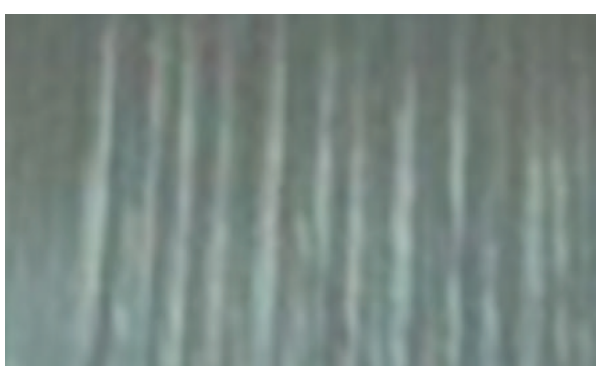

(a) Without control

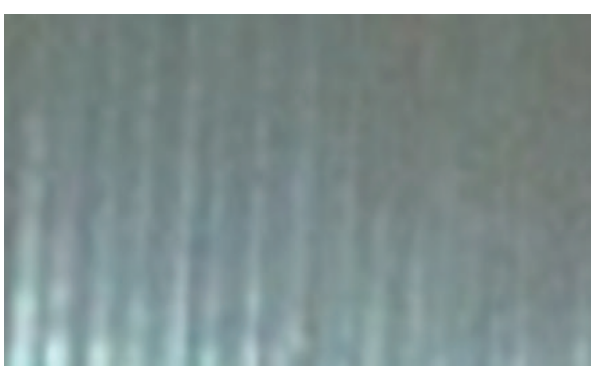

(b) With control

FIGURE 6: Machined surface quality. Workpiece: 302; tool: YT15; cutting parameters: $v=2 \mathrm{~m} / \mathrm{s}, \alpha_{p}=3 \mathrm{~mm}, f=0.1 \mathrm{~mm} / \mathrm{r}$.

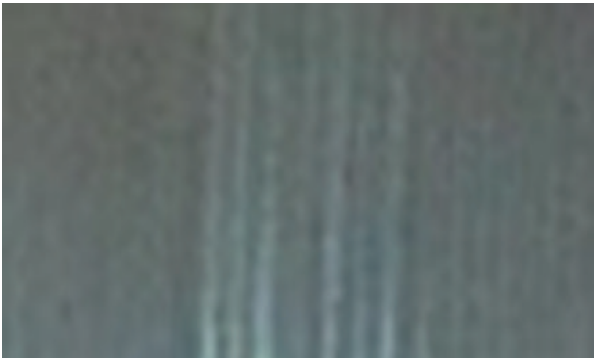

(a) Without control

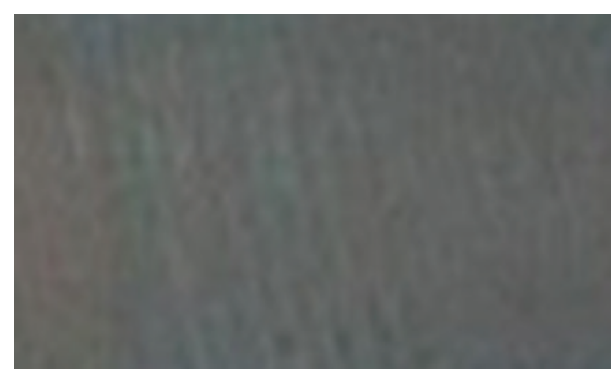

(b) With control

FIGURE 7: Machined surface quality. Workpiece: 302; tool: YT15; cutting parameters: $v=4 \mathrm{~m} / \mathrm{s}, \alpha_{p}=3 \mathrm{~mm}, f=0.1 \mathrm{~mm} / \mathrm{r}$. 
TABLE 1: Experimental data.

\begin{tabular}{lccc}
\hline Workpiece & 302 & 302 & 302 \\
$n(\mathrm{~m} / \mathrm{s})$ & 1500 & 3000 & 5000 \\
$\alpha_{p}(\mathrm{~mm})$ & 3 & 3 & 3 \\
$f(\mathrm{~mm})$ & 0.09 & 0.09 & 0.09 \\
Surface roughness & & & \\
$\quad$ With control & 0.91 & 0.75 & 0.45 \\
$\quad$ Without control & 1.12 & 0.95 & 0.60 \\
\hline
\end{tabular}

Two topics, applied research of the nonlinear control system with time-delay and the linear descriptor discrete control system with time-delay, will be analyzed in the future.

\section{Conflict of Interests}

The authors declare that there is no conflict of interests regarding the publication of this paper.

\section{Acknowledgments}

The Project was sponsored by the Scientific Research Foundation for the Returned Overseas Chinese Scholars, State Education Ministry (2013 no. 8). The authors would like to thank the Shanghai Jiaotong University State Key Laboratory of Mechanical System and Vibration for their suggestion in the course of the experiment. Also, the authors would like to thank the editor and the reviewers for their constructive comments and suggestions which improved the quality of this paper.

\section{References}

[1] F. Erich, R. Christian, R. Tobias, and S. Bernhard, "Processing short-term and long-term information with a combination of polynomial approximation techniques and time-delay neural networks," IEEE Transactions on Neural Networks, vol. 20, no. 9, pp. 1450-1462, 2009.

[2] M. Rawat, K. Rawat, and F. M. Ghannouchi, "Adaptive digital predistortion of wireless power amplifiers/transmitters using dynamic real-valued focused time-delay line neural networks," IEEE Transactions on Microwave Theory and Techniques, vol. 58, no. 1, pp. 95-104, 2010.

[3] J. Pittner, N. S. Samaras, and M. A. Simaan, "A new strategy for optimal control of continuous tandem cold metal rolling," IEEE Transactions on Industry Applications, vol. 46, no. 2, pp. 703-711, 2010.

[4] N. Stefanovic and L. Pavel, "Robust power control of multi-link single-sink optical networks with time-delays," Automatica, vol. 49, no. 7, pp. 2261-2266, 2013.

[5] W. Zhang, H. Su, Y. Liang, and Z. Han, "Robust stability test for uncertain discrete-time systems: a descriptor system approach," Latin American Applied Research, vol. 41, no. 4, pp. 359-364, 2011.

[6] W. Zhang, H. Su, F. Zhu, and D. Yue, "A note on observers for discrete-time lipschitz nonlinear systems," IEEE Transactions on Circuits and Systems II: Express Briefs, vol. 59, no. 2, pp. 123-127, 2012.
[7] E. Fridman and U. Shaked, "A descriptor system approach to $H_{\infty}$ control of linear time-delay systems," IEEE Transactions on Automatic Control, vol. 47, no. 2, pp. 253-270, 2002.

[8] W. Zhang, Q. Y. Xie, X. S. Cai, and Z. Z. Han, "New stability criteria for discrete-time systems with interval time-varying delay and polytopic uncertainty," Latin American Applied Research, vol. 40, no. 2, pp. 119-124, 2010.

[9] O. M. Kwon, S. M. Lee, and J. H. Park, "On the reachable set bounding of uncertain dynamic systems with time-varying delays and disturbances," Information Sciences, vol. 181, no. 17, pp. 3735-3748, 2011.

[10] J. V. Salcedo and M. Martínez, "LPV identification of a turbocharged diesel engine," Applied Numerical Mathematics, vol. 58, no. 10, pp. 1553-1571, 2008.

[11] C. Briat, O. Sename, and J. F. Lafay, "Memory-resilient gainscheduled state-feedback control of uncertain LTI/LPV systems with time-varying delays," Systems and Control Letters, vol. 59, no. 8, pp. 451-459, 2010.

[12] F. Wu and K. M. Grigoriadis, "LPV systems with parametervarying time delays: analysis and control," Automatica, vol. 37, no. 2, pp. 221-229, 2001.

[13] B. Lu, F. Wu, and S. Kim, "Switching LPV control of an F-16 aircraft via controller state reset," IEEE Transactions on Control Systems Technology, vol. 14, no. 2, pp. 267-277, 2006.

[14] S. Lim and J. P. How, "Modeling and $H_{\infty}$ control for switched linear parameter-varying missile autopilot," IEEE Transactions on Control Systems Technology, vol. 11, no. 6, pp. 830-838, 2003.

[15] B. S. Hong, W. J. Su, T. Y. Lin, L. K. Chen, and Y. S. Chen, "Gametheoretic linear parameter-varying control with multiple L2gain objectives upon energy-motion regulation of electric bikes propulsion," IET Control Theory \& Applications, vol. 7, no. 7, pp. 966-974, 2013.

[16] M. Tanelli, D. Ardagna, and M. Lovera, "Identification of LPV state space models for autonomic web service systems," IEEE Transactions on Control Systems Technology, vol. 19, no. 1, pp. 93-103, 2011.

[17] S. Skoczowski, S. Domek, and K. Pietrusewicz, "Model following PID control system," Kybernetes, vol. 32, no. 5-6, pp. 818-828, 2003.

[18] K. M. Chang, "Robust model following control for uncertain systems with input nonlinearities," JSME International Journal, Series C: Mechanical Systems, Machine Elements and Manufacturing, vol. 45, no. 1, pp. 187-193, 2002.

[19] S. Okubo, "A design of nonlinear model following control system with disturbances," Transactions of the Society of Instrument and Control Engineers, vol. 21, no. 8, pp. 792-799, 1985.

[20] T. Akiyama and S. Okubo, "Design of the model following control system with time delays," IEEJ Transactions on Electronics, Information and Systems, vol. 118c, no. 4, pp. 497-502, 1998.

[21] D. Wang and S. Wu, "Model following control and application in cutting vibration control," in Proceedings of the International Conference on Mechatronics and Control (ICMC '14), pp. 11991202, Jinzhou, China, July 2014.

[22] D. Z. Wang, S. J. Wu, and S. Okubo, "State predictive model following control system for linear time delays," International Journal of Automation and Computing, vol. 6, no. 2, pp. 186-191, 2009.

[23] D. Wang and S. Okubo, "A design of model following control system for linear neutral system with time delays," IEEJ Transactions on Electronics, Information and Systems, vol. 128, no. 11, pp. 1657-1663, 2008 (Japanese). 
[24] D. Wang, S. Wu, and S. Okubo, "Design of the state predictive model following control system with time-delay," International Journal of Applied Mathematics and Computer Science, vol. 19, no. 2, pp. 247-254, 2009.

[25] X. Zhang, P. Tsiotras, and C. Knospe, "Stability analysis of LPV time-delayed systems," International Journal of Control, vol. 75, no. 7, pp. 538-558, 2002.

[26] R. Zope, J. Mohammadpour, K. Grigoriadis, and M. Franchek, "Delay-dependent output feedback control of time-delay LPV systems," in Control of Linear Parameter Varying Systems with Applications, pp. 279-299, Springer, 2012. 


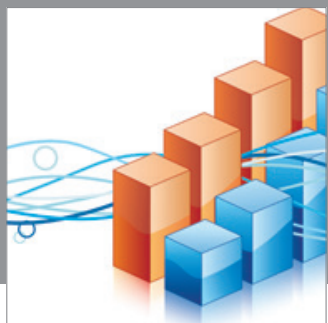

Advances in

Operations Research

mansans

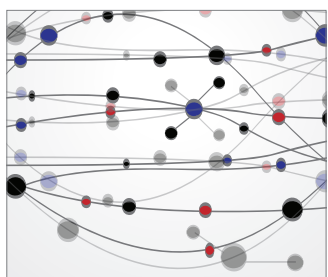

The Scientific World Journal
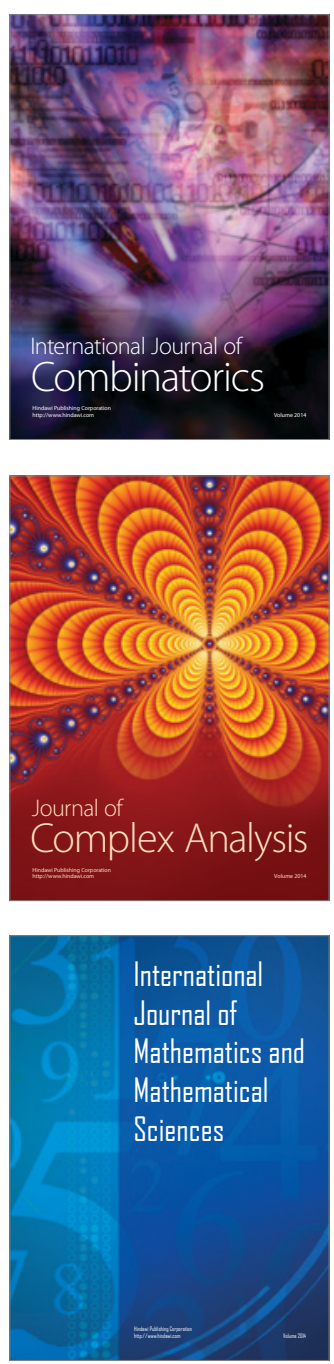
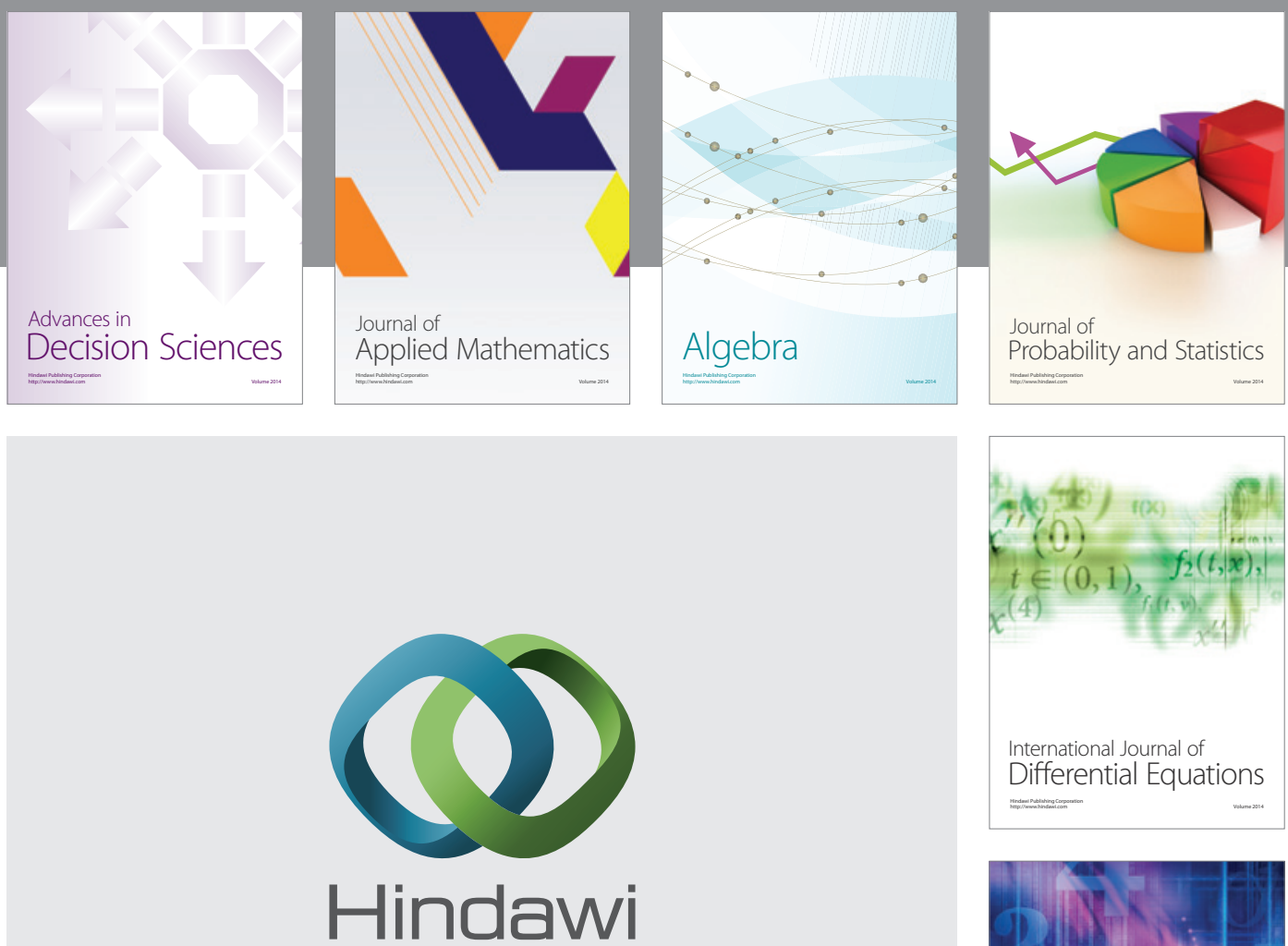

Submit your manuscripts at http://www.hindawi.com
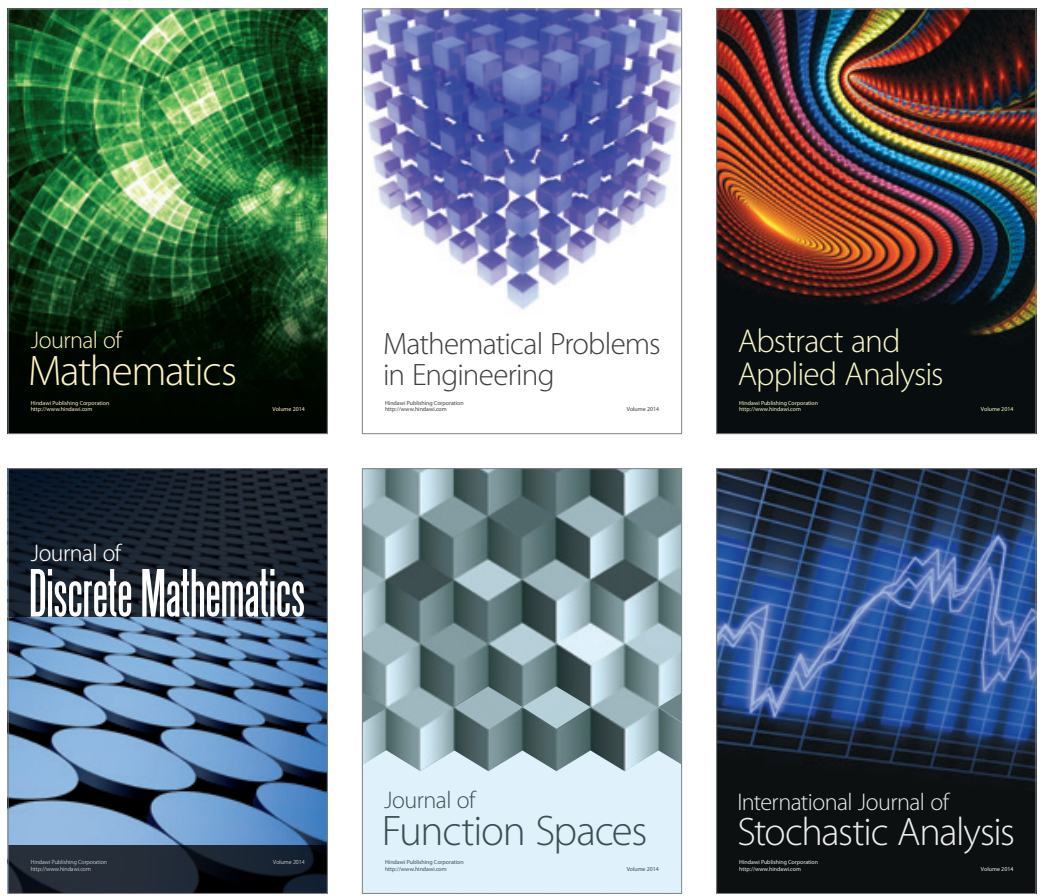

Journal of

Function Spaces

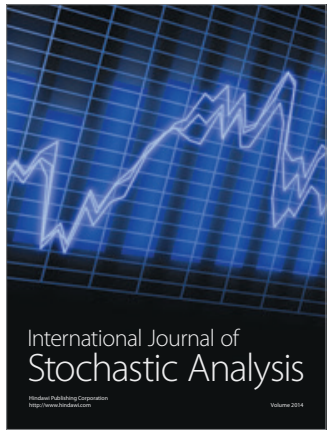

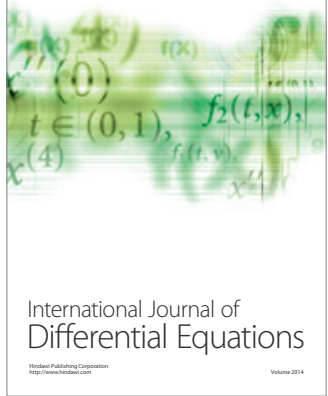
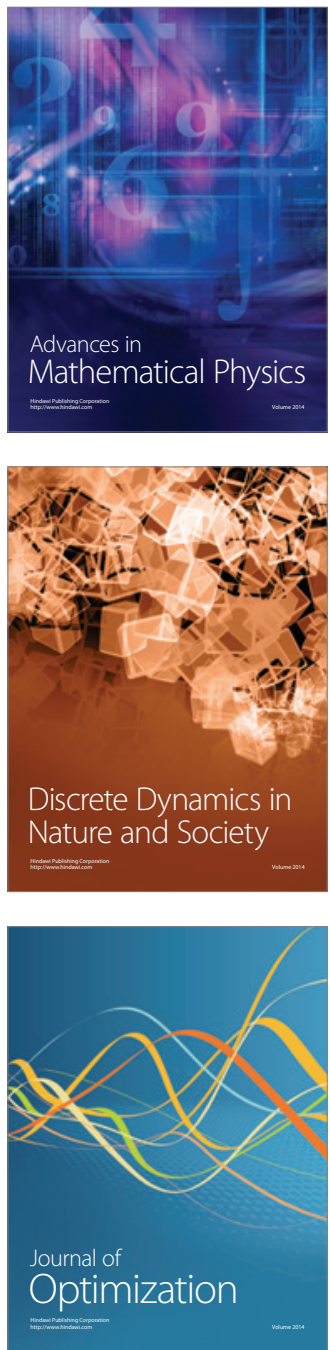